\title{
Elements of Document Design ${ }^{1}$
}

\author{
Ricky Telg and Ashley McLeod-Morin²
}

This publication on the elements document design is the third of a five-part series on document design. This series also covers the document design process, principles of document design, graphic file formats, and brochure and newsletter design.

\section{Introduction}

In addition to the overall principles of document design are the specific elements of document design. Where the principles of document design provide considerations for overall document layout, the elements of document design focus on these specific visual elements that make up the visual content of the document: text and typefaces, visuals, graphics, color, and white space. This publication series is created for anyone with an interest in designing effective documents.

\section{Text and Typefaces}

Text is any size, shape, and placement of the printed word in your document. Text can be placed on your document in the following ways:

- Full justified, also called "justified": All of the text is "flush" on both the right and left sides. To accomplish this, the words in a sentence and letters inside of words can become stretched to fill the space on a particular line.

- Left justified, also called "ragged right": The text is "flush" on the left-hand side of each page or column of text, but is "ragged" or uneven on the right-hand side.

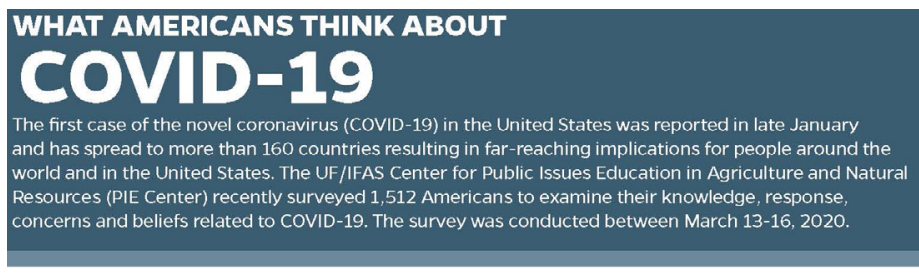

TWO-THIRDS OF AMERICANS RANK COVID-19 AS THE NO. 1 PUBLIC HEALTH CONCERN
According to a recent survey conducted by the UF/ IFAS PIE Center, two-thirds of Americans ranked COVID-19 as the No. 1 public health concern, even when compared to influenza, HIV and Ebola.

Americans were also asked about their

information-seeking behaviors. More than 40\% of respondents reported seeking information about COVID-19 very often within the past month. Another $22.7 \%$ percent of respondents indicated seeking information occasionally.

Respondents indicated they were most likely to seek COVID-19 information from the following sources: Centers for Disease Control and Prevention websites, Department of Health websites, personal healthcare provider and the World Health Organization website.

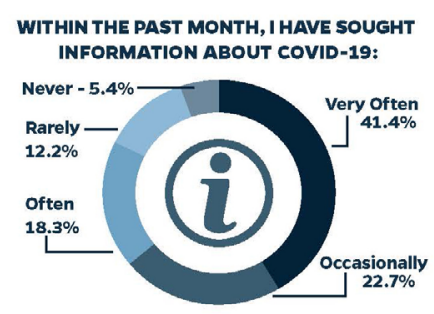

Three-fourths of respondents reported being concerned about the impact of COVID-19 on increasing food prices. Eighty-six percent of respondents reported being concerned about the impact of the virus on their state's economy. Nine in 10 people were concerned about the United States economy.

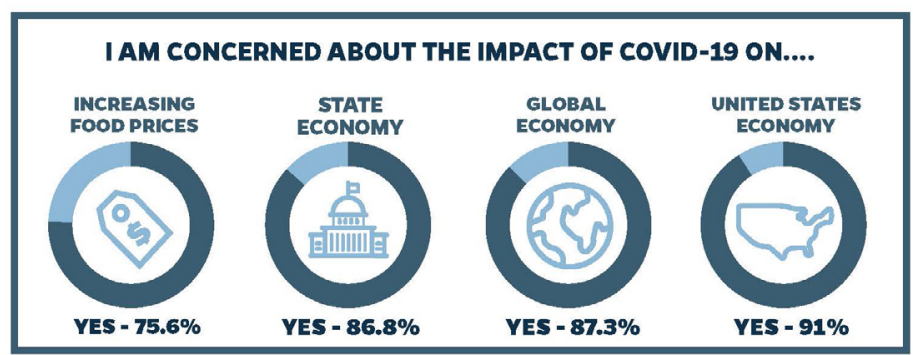

Figure 1. The UF/IFAS Center for Public Issues Education in Agriculture and Natural Resources develop issue guides that utilize various visual elements, including varying typefaces, graphics, color, and white spaces. https://piecenter.com/covid-19/

1. This document is WC129, one of a series of the Department of Agricultural Education and Communication, UF/IFAS Extension. Original publication date April 2021. Visit the EDIS website at https://edis.ifas.ufl.edu for the currently supported version of this publication.

2. Ricky Telg, professor, Agricultural Communication, Department of Agricultural Education and Communication; and Ashley McLeod-Morin, media coordinator, UF/IFAS Center for Public Issues Education in Agriculture and Natural Resources; UF/IFAS Extension, Gainesville, FL 32611.

The Institute of Food and Agricultural Sciences (IFAS) is an Equal Opportunity Institution authorized to provide research, educational information and other services

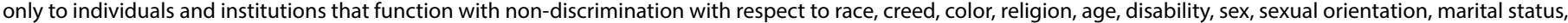

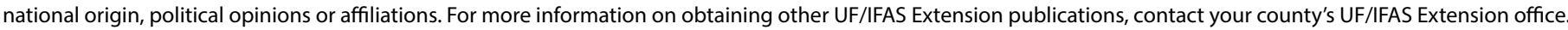
U.S. Department of Agriculture, UF/IFAS Extension Service, University of Florida, IFAS, Florida A \& M University Cooperative Extension Program, and Boards of County Commissioners Cooperating. Nick T. Place, dean for UF/IFAS Extension. 
- Center justified, or "centered": The text is centered on the page. This is commonly used for headings for brochures, fliers/handouts, and in some newsletters.

- Right justified: The text is "flush" on the right and uneven on the left. Right-justified text is rarely used in most documents, except to line up all of a column to the right-hand side.

Text also can be boldfaced (or bolded), italicized, or underlined. However, these text styles should be used only to draw readers' attention; they should not be overused. For example, it is recommended that italics be used for short phrases, such as for direct quotations in a brochure or handout, rather than for long passages.

In more advanced layout and design programs, you can adjust the space between letters, words, and lines. You can get some interesting effects by adjusting text spacing. Kerning is the space between letters. Tracking is the amount of space between words. Leading (pronounced with a short "e" as in "bedding") is the amount of space between lines of text. Look at some documents to see how close or far apart the spacing is between letters, words, and lines. Adjust the kerning, tracking, or leading to imitate the spacing that you like for your document.

Typeface-also called type or font-is the actual look of the letters. Type usually is classified into two categories: serif type (also called serif font) and sans serif type (or sans serif font).

Serif fonts are those where the letters have "feet" or "tails," such as the Times New Roman typeface. Serif fonts are a good choice for printed materials because the "feet" at the bottom of letters make it easier for readers to follow each line of text. Serif fonts trace their history to ancient Rome. Letters were chiseled into buildings' walls. However, the straight-edged letters created cracks in the walls. To avoid that, Roman architects began putting horizontal edges on the top and bottom of the vertical lines forming the letters. Rounding off the letter by adding these "feet" and "tails" changed the direction of the stress on the walls, eliminated cracks in the walls, and introduced the concept of serif typeface to Western civilization.

Sans serif means "without serif." Simply, sans serif fonts do not have "feet" or "tails" on their letters. Arial and Helvetica are examples of sans serif fonts. Sans serif fonts are viewed as more contemporary than serif fonts because they have a cleaner look; many sans serif fonts have been in use only since the 1970s. Sans serif fonts usually are not good choices for a lot of text on a page, because they are more difficult to follow across the page without the "feet" for each letter. Sans serif fonts are recommended for text that is projected onto a screen or read on a television screen or computer screen. Sans serif fonts also are a good choice for short headlines and brief photo captions.

When designing any document, the most important aspect to keep in mind about text and typeface is for the lettering to be large enough and legible enough to be read easily. You also should use no more than two typefaces in a document. Use uppercase/lowercase lettering in your document. Only use all uppercase lettering when you want to call attention to a specific word or short phrase. Readers see all uppercase lettering as if the document designer is shouting at them. Research also indicates that uppercase/lowercase is easier to read. As a result, the federal government is requiring cities across the country to change street-name signs from all capital letters to uppercase/lowercase letters (Copeland, 2010).

Headings, titles, and captions are specific aspects of text applications. Headings and titles orient readers to the start of a topic. They should be briefly worded. Most headings and titles are bolded and larger than the document's other text. Captions, also known as cutlines, are brief descriptions placed under photographs or graphs. Usually a caption provides information on who is in the photograph, what is going on, where and when the action happened, and why the action is significant. Studies have shown that most people read captions immediately after they read the headlines.

\section{Visuals}

Visuals are anything in pictorial form, such as photographs, drawings/illustrations, clip art, and graphs and charts. The functions of visuals are to grab the reader's attention and to support or provide explanation to the document's overall message.

Photographs show the actual physical images of objects. Photographs have the advantage of realism. One disadvantage is the extraneous details in the photograph that may detract from the message.

Drawings/illustrations can depict imaginary objects or real objects difficult to photograph. Drawings can show only the parts the reader needs to see. Drawings give you the advantage of control by eliminating extraneous detail and emphasizing what you want to emphasize. Illustrations should be clean and simple. 
Clip art is an alternative to drawings. Clip art can be found online.

Graphs and charts provide information, usually statistics or numbers, in an easily understandable visual form. Graphs and charts should be clear, uncluttered, suited for the reader, legible, and placed near where they are mentioned in the document. Graphics and charts must have brief but understandable titles. Some graphs and charts will have a key that explains symbols used in the visual. Graphs and charts come in different forms, based on the type of information that is being communicated. Some of the most common ones are infographics, bar charts, pie charts, and line graphs. If your graphs and charts are in black and white, be sure that readers can differentiate between the shadings of the different sections of a pie chart or bar graph, for example.

- Infographics is the term to describe the use of visual elements to communicate complex information quickly and clearly. Infographics use recognizable images to represent specific quantities. For example, instead of using a line graph, a document designer may use an illustration to represent numerical data. The illustration adds visual appeal to the information. The Snapshots features used in USA Today are good examples of infographics.

- Bar graphs show comparison at different times, locations, and conditions. Bar graphs are easy to understand and can be either vertical or horizontal.

- Line graphs display trends over time in amounts, sizes, rates, and other measurements on lines. Line graphs give an at-a-glance impression of trends and forecasts of data. You should have no more than four or five lines presented in a line graph. It is best to distinguish different lines by using different colors or thicknesses. Show current data with solid lines, and illustrate future data with broken lines.

- Pie charts are best at showing what parts make up the whole and at comparing relative sizes of the parts. A good example of a pie chart would be to show the ethnic background of all of the students in a school. Pie charts are most effective with six or fewer sections or "slices."

\section{Color}

Color can be used to draw attention because visual elements with color have greater visual weight. Certain colors also are interpreted in specific ways by most people. Warm colors are reds, yellows, and blends of those two colors (orange). These colors are related to heat, fire, and the sun. Cool colors - blues and greens - relate to the sky, sea, and wilderness. Depending on what message you are trying to get across to your audience, you may want to use one of the following colors:

- Red is the most dramatic color. It excites and stimulates people. Red is often associated with aggressive behavior, passion, success, and impulse. Use red sparingly, because it is such a "hot" color.

- Bright yellow often is associated with health and wellbeing. Yellow is also associated with caution. For example, all traffic signs that pertain to caution - such as yield signs-are in yellow.

- Blues are associated with tradition, orderliness, and stability. Light blues are associated with cleanliness. Dark blue colors seem to have a calming effect. Purple is seen as daring, royal, and elegant.

- Greens provide a sense of nature and regeneration. Green is used by many environmental organizations.

- White is a symbol of purity and innocence in Western countries.

- Black usually signifies finality, ending, and death in Western countries.

\section{Graphics}

Graphics are lines, borders, and boxes in your document. These are used to highlight or draw attention to an area of the document. To emphasize a particular part of your document, you may place a border around a photograph. Graphics also are used to separate visual elements. For example, a box around a newsletter story could separate it from other stories on the page. Small lines under a photograph's caption could be used to separate the caption from the rest of the story. Graphics should be used sparingly. Do not place a box or border around each visual element on your page. If you use shaded boxes, make sure that the shading is not too dark. A shading of 10 percent is usually all you need. A shading of 20 percent or greater may be too dark to read for the text.

\section{White Space}

White space (also called "blank space" or "negative space") is the area not taken up with text or images. White space is used to create a sense of openness. Too many elements on a page can look confusing and detract from the overall visual appeal of your page. White space separates paragraphs and provides margins at the edges of your pages. Areas occupied by text or images are called positive space. 


\section{Additional Information}

Copeland, L. (2010). "Can You Read This? Or, Is This Easier on the Eyes?" USA Today, vol. 29, no. 28 (October 24,

2010): $1 \mathrm{~A}$.

Diggs-Brown, B., \& Glou, J. (2004). The PR styleguide: Formats for public relations practice. Belmont, CA: Wadsworth.

Kimball, M. A., \& Hawkins, A. R. (2008). Document design: A guide for technical communicators. Boston, MA: Bedford/ St. Martin's.

Marsh, C., Guth, D. W., \& Short, B. P. (2005). Strategic writing: Multimedia writing for public relations, advertising, sales and marketing. Boston, MA: Pearson Education.

Telg, R. \& Irani, T. A. (2012). Agricultural communications in action: A hands-on approach. Clifton Park, NY: Delmar. 